\section{Making Philosophical Sense of Indigenous Pacific Research}

Kabini F. Sanga

\section{Introduction}

As knowledge systems of indigenous peoples receive greater global, regional, national and local attention, so too does the call for recognition of these systems. Indigenous Pacific research is no exception. Writing on indigenous Kawara'ae research, Solomon Islander, Gegeo (1998:309) sought recognition for his thesis from an established non-Pacific academic. He wrote: 'Lest the skeptic feel that this line of argument is merely the unsubstantiated personal views of a 'disgruntled Other' seeking legitimacy for indigenous systems of knowledge, here is how the internationally renowned anthropologist Laura Nader saw the issues." Gegeo then went on and quoted Nader's supposed support.

In a recent article, Fiji-based academics Huffer and Qalo (2004:108) lamented the ongoing dismissal by and ignorance in academia of Pacific thought. The authors observed: "The lack of a coherent voice to promote Pacific thought or philosophy means that it is discounted, particularly when it comes to policy-making." The authors argued that Racific thought must influence policy on Pacific development and that this was possible only if a credible body of thought was mounted.

Within education, numerous calls have been made by Pacific educators, including Thaman (1988), Nabobo (1994), Taufe'ulungaki (1994) and more. Speaking specifically about education in Vanuatu, Sanga and Niroa (2004: 14) had this to say: "After two decades of 'listening' to 'outside voices' without seeing overwhelmingly convincing positive results, it appears that the time is here for the cultivation of local agenda, NiVanuatu interpretations and man ples perspectives. An integral part of this... is to hear indigenous voices, represented by edicational ideas, forms, philosophies and practices that have been nurtured in the islands for centuries but have not been incorporated into the discussions on education." These two authors suggested that Ni-Vanuatu could begin to gain recognition by writing down their understandings of the world.

A number of other strategies have been tried by and for Pacific peoples in Aotearoa New Zealand. In 2002, the Ministry of Education commissioned a project to draw up guidelines for doing research on and with Pacific, peoples. In the same year, the Auckland-based Pacific Business Trust commissioned another report calling for advice on how research on and with Pacific communities can be made credible to the communities as well as to the research undertaking (Sanga and Pasikale 2002). Other sectors of the community, such as health and social services, have also produced institutional guidelines for researching Aotearoa Pacific communities. A common feature of these strategies has been their tendency to use strong cultural arguments for recognizing Pacific researcb.

At the university level, teaching courses on Pacific thought has been a way of gaining recognition. The nature and levels of courses vary considerably. At the University of the South Pacific, Konai Thaman teaches Pacific educational epistemology as an undergraduate course. At Auckland University, Tupeni Baba teaches a post-graduate course on Pacific research. Speaking about the post-graduate course on Indigenous Pacific research at Victoria University of Wellington, Penetito and Sanga (2002:36) concluded their justification for the course by "leaving the last word to Denis Goulet", a non-Pacific academic. Again, these authors appeared to fall back on the support of a non-Pacific person, to say the final word.

The calls for recognition of indigenous Pacific research and the justifications for these are numerous. It is, however, still too early to ascertain which strategy is likely to be effective towards achieving recognition.

In this short chapter, I suggest a strategy for conceptualizing indigenous Pacific research in its search for credibility. I begin with the thesis that indigenous Pacific research is based on a philosophy of human nature. I examine key philosophical assumptions, which undergird indigenous Pacific research. I argue that the tendency to fight politically for academic legitimisation is not effective and not necessary as it is logical to conceptualise indigenous Pacific research philosophically. I propose, instead, for efforts by Pacific researchers to be spent on developing Pacific research within its own philosophical orientation, since it is from such attention that confidence and credibility are more likely to be achieved. My analysis is based on Burrell and Morgan's (1992) sociological approach to organizational change. In briet, the basic thesis of these authors' approach is that all theories of social science are based on a set of philosophical assumptions of the social world and how it is to be investigated. Instead of using the model in its entirety, I have limited myself to the subjective-objective dimensions only. As well, I have included the factor of axiology in the discussion though this is not part of Burrell and Morgan's model. 
Clarifications

Before going further, a number of clarifications need to be made. First, indigenous Pacific research is not a single body of thought. Huffer and Oalo (2004) noted that there is, as yet, no recognizable and agreed-upon Pacific thought. I use indigenous Pacific research as a presupposition and in a developmental way. I do not envisage a single Pacific thought. I only see indigenous Pacific research in a paradigmatic sense, sharing a set of philosophical orientations.

Second, my usage of the term "Pacific" does not include Aotearoa New Zealand where considerable and exciting work relating to Măori, as an indigenous Pacific people, has been undertaken. By not including Māori, it is easier to see the underdeveloped status of indigenous Pacific research and hence its need for nurturing. Aotearoa - based Pacific peoples, however, are included.

Third, the philosophical debates on research have a long and complex history. As well, my experience of indigenous Pacific research is limited. I do not profess to understand both the debate and indigenous Pacific research fully. Notwithstanding, I still wish to make a contribution to the discussion by suggesting a conceptualization of the emerging body of indigenous Pacific research.

\section{The debates}

Indigenous Pacific research is based on a set of assumptions. In talking about indigenous Pacific research, $Y$ assume, for instance, that peoples of the Pacific have their own worids that they influence and control. I further assume that Pacific peoples are both different to each other as well as to other peoples that are not of the Pacific. Indigenous Pacific research is also based on a set of presuppositions. These are ideas of time, space, the self self-image and attitudes towards others. In discussing indigenous Pacific research, I presuppose, for instance, that Pacific peoples see time as integral to relationships, rather than divorced from these. I also presuppose that Pacific peoples see their ancestors, including those long gone, as members of their worlds and masters of their environments.

The assumptions have a molding influence on research experience. They act like a directing force on the practice of research. In the paragraphs that follow I examine key philosophical assumptions, hence, the different debates relating to ontology, epistemology, axiology and methodology. Due to time constraints, I only offer the indigenous Pacific research perspective to each of the debates.
Ontological debate

Ontology refers to one's social reality. In the world of humans, it is that which is considered real or not real. When considering indinas, it is that research, there is an ontological debate, which is based on two opposing assumptions, as follows:

1. That the social world for people is tangible and external to their cognition, whether or not they perceive this.

2. That the social world for people is intangible and internal to their cognition.

Indigenous Pacific research assumes that the social world and hence the phenomenon under investigation is intangible, 'soft', and internal to people's cognition. As such, people use labels, names and concepts to describe and explain that 'reality'. It therefore follows that 'reality' is subjective to the context and people. It expresses the social, spiritual and cultural worlds of a people. It is experienced. It is particularistic to time and space. It is local. 'Reality', in this instance, is what people 'make it'. It changes. It includes other realities. It embraces change, introductions and trends and makes these its own.

Let us look at some examples. Speaking about his own community, Teaero (2003:106) explains that the "Kiribati world is a huge world indeed, consisting of the sea, land, sky and the world of the departed ancestors." Similarly, Fijian author Nabobo (2003) describes how the viravura 'earth' and lagi 'heavens' and bulu 'afterlife' are integrated entities and determine what constitutes his world. In both examples, I Kiribati and Fijians alike would express their worlds in descriptions and metaphors that have become part of their practices and ways of life.

Using an example from education, Fijian mathematician Bakalevu (2001:15) explains that the 'reality' for Fijian mathematics students is "a less well-developed sense" for numbers. In another example from education, Pasikale and Tupuola (1999) noted that Tokelau students are overly represented, relative to other Aotearoa ethnic groups, in the proportion of students who leave school without a formal qualification. These examples are based on the assumption that social reality for Pacific peoples is intangible and internal to their cognition.

In an ontological debate, the challenges for indigenous Pacific research are numerous. Three examples are given. First, the need exists to undertake research that demonstrates the diverse, rich and complex 
realities of Pacific peoples. Second, there is a temptation to see Pacific realities against other realities as if they are inferior, underdeveloped or are sub-sets of other realities. Third, retaining the autonomy and authenticity of realities is likely to be challenging, particularly for transcriptions and co-constructions of Pacific realities. The point worth noting is that indigenous Pacific research is based on a particular assumption of social reality, which gives it credibility and mana. Stray from this in an ontological debate and you're over-exposing your belly!

\section{Epistemological debate}

Episteme is Greek for knowledge. The word epistemology refers to the grounds of knowledge. When examining indigenous Pacific research, there is an epistemological debate, which centers on how people know or understand their social reality. Moreover, the debate is about how knowledge is communicated as truth, to others.

In an epistemological debate, there are two basic opposing assumptions, as follows:

1. In research, one looks for universal laws, regularities and causal relationships of realities in order to explain and predict these realities.

2. In research, one looks for insider or particularistic constructions, uniqueness, relativist knowledge, using frames of the participants.

Indigenous Pacific research assumes that knowledge is relativist and inseparable from the context and the social realities of Pacific peoples. Consequently, the way to explain, know and understand is by using constructs, frames and metaphors that are intelligible to that knowledge.

Some examples of indigenous Pacific research epistemology: In explaining community development, Gegeo (1998:307) speaks about the Kwara'ae concept of gucamatu'tanga as having more to do with 'standing on one's own' and 'doing things on one's own'. To the Kwara'ae, this is their knowledge with its own grounds of legitimization and truth-testing. In another example, Hereniko (1995) says that Rotuman historical knowledge is imprecise so dates are not deemed important. Similarly, Fijian researcher Bakalevu (2001:7) asks, "Is sega zero or little?" Being imprecise, how does a researcher find it?

The particularistic nature of framing knowledge is important. Thaman (2003) shows this by her use of kakala as a framework to explain teaching and learning for Tongans. According to Thaman, kakala is culturally inclusive. It utilizes Tongan knowledge, understandings and worldview. Moreover, kakala is holistic and values relationships. Another Tongan academic, Manu'atu (2000) has demonstrated that relational notions of mälie and mäfana are the key to good pedagogy and learning for a group of Tongan students in Aotearoa New Zealand.

In reference to the insider construction of I-Kiribati epistemology, Teaero (2003) explains that Kiribati knowledge is controlled by the boto (a wise elder or teacher) because of the belief that the origin of knowledge is supernatural and is therefore guarded zealously by the boto.

The ways of passing knowledge on are also particularistic. In the Kiribati context, knowledge is orally communicated by the boto. In parts of Polynesia, certain domains of knowledge are constructed and disseminated during talanoa sessions. Among the Tikopia people, key historical knowledge is danced and sung, rather than being told as a story. Within urban settings, some knowledge from the indigenous Pacific region (IPR) is now constructed and passed on through videos, camera and on websites. Knowledge learning also varies. Speaking of his own Mogei people of Papua New Guinea, Mel (2003) explains that children control the length and pace at which they learn certain knowledge. Again, the examples of Pacific epistemology show that they are premised - on the assumption that knowledge is particularistic and relativist.

In an epistemological debate, the challenges for indigenous Pacific research are many. Three are presented. First, external epistemological structures are readily available and it is difficult to resist using these to investigate an indigenous Pacific phenomenon. Second, where indigenous discourse is taking place, having indigenous Pacific research anchored in Pacific epistemology is going to be difficult particularly in a cross-paradigmatic discourse. Third, where Pacific epistemologies appear to be contradicting each other, the danger exists of failing to explain the differences and similarities in a philosophically rigorous manner. A key consideration is this - that indigenous Pacific research needs to remain consistent with its epistemological assumptions - as it aspires to establish itself in academia.

\section{Axiological debate}

The word axiology refers to what is of value. When considering indigenous Pacific research, there are two basic assumptions that are axiological in nature. These are stated as opposing perspectives, as
follows: 
1. Thit the social world and research of that world is value-free.

2. That the social world and research of that world is value-bound.

Indigenous Pacific research assumes that research is value-bound and is therefore influenced by the researcher, the researched, the conceptual framework used, the methodology and the context.

Given this assumption about the value-laden nature of research, any investigation is considered political, advancing multiple interests, realities and results. In other words, research findings are value-laden, open to contest and representative of multiple meanings. Truth, therefore, is value-bound because it is historically, socially and spacially set. Because by its nature, reality is deemed to be constructed, truth and knowledge about it is therefore partial and tentative. Consequently, what gets to be valued differs in time and space.

Here are two examples of axiological issues in indigenous Pacific research: In speaking about Tongan research, Thaman (1988) explains that a prerequisite to understanding Tongan behaviour is knowing the values that are considered of importance to Tongans. She lists these as "emphasis on the supernatural, rank, authority, kinship relationships, concrete and specific context and restraint behaviour". In another Polynesian context, Furivai (2003) explains that according to Rotuman oral tradition, for anything to be considered of value, it must preserve and promote Rotuman culture. Consequently, knowledge is considered valuable if it is useful for Rotuman living. The above examples point to the value-laden nature of reality, knowledge and research.

Ways of describing knowledge, explaining and reporting it must be those that allow for backgrounds, multiple realities, processes and contextual protocols to be captured. As mentioned, in indigenous Pacific research, the logic of research is value-laden and is therefore contestable.

The challenges for indigenous Pacific research are wide-ranging. Three are presented. First, a challenge relates to the extent to which any particular Pacific research is consistent in an axiological manner. Given the value-laden nature of research, establishing the trustworthiness of the phenomenon under investigation, its explanations, conclusions or understandings about it, is complex. Second, a major challenge relates to how indigenous Pacific research will deal with any agenda which is political and democratic in nature. This is particularly so if funding for research comes from sources that are external to a Pacific community. Third, within small Pacific communities, the value-laden nature of research is likely to result in tensions and outright conflicts within these communities. Rather than be overwhelmed by these challenges, indigenous Pacific research is more likely to be respected for its faithfulness to its axiological orientation.

Methodological debate

The debate at this level relates to two basic assumptions, as follows:

1. That research methods and strategies are to test hypotheses, systematic protocols and techniques.

2. That research methods and strategies are to focus on obtaining contextual details, insider perspectives, particularities, as these unfold during investigation.

Indigenous Pacific research subscribes to the second assumption. - Consequently, the more appropriate research strategies are those that are qualitative in nature becanse they better serve the methodological purposes of Pacific research. A key purpose is the ability to obtain rich contextual details. As well, research must adequately stress process considerations and be able to capture realities as they unfold. As mentioned earlier, the active participation of insiders is integral to indigenous Pacific research. This allows for multiple realities to be captured, particularities to be spotlighted and each 'voice' to be heard. Such results can only be achieved when appropriate research designs and strategies are used.

The basic argument by proponents of indigenous Pacific research is this: that research with/of Pacific peoples must use strategies that are Pacific in nature. Three examples of this debate, from the indigenous Pacific research view, are given. Samoan researcher Tupuola (2000) for instance, argues that the design of research involving Samoans must take into account the relational aspects of the participants and the researcher. As well, she thinks that participants should have a say in what the research questions should be. Hereniko (1995) suggests that research involving Rotumans must use stories, songs, dances, enactments and personal anecdotes, as these are the strategies used by Rotumans in their day-today existence. Siosiana Ungatea (personal conversation, 2002) of Tonga rejects the use of university ethics committee procedures as inappropriate for Tongan research. Instead, she suggests that Tongan protocols be used, as they take into account local societal practices and codes of ethics.

The challenges for indigenous Pacific research are considerable. First, the research strategies that are FakaTonga, Fa'aSamoa or Pacific in nature 
must be trialed, described and used appropriately in a variety of contexts. Second, the need exists for rigourous debate on indigenous Pacific research methodology to improve designs, protocols and research strategies, including tests of trustworthiness. Third, the use of complex strategies such as dance, song or dreams, is untested in systematic Pacific research. It becomes more challenging when normal family and community activities are typically the settings for Pacific research. For instance, how do researchers who are relatives of respondents ensure ethical and rigourous research behaviour? This and many more methodological questions can be posed. It is necessary, however, to ensure clarity on the basic methodological assumptions of indigenous Pacific research and to remain true to it.

\section{Tentative observations}

In examining the academic discourse on indigenous Pacific research, Pacific researchers have tended to argue their cases along political and cultural lines. Hence, Hereniko (1995) rejected what he termed imperialistic research practices by outsiders when undertaking research on Rotumans. Tupuola (2000) anchored her argument on the irrelevance of cultural impositions from outside the Pacific. Others, including Pene, Taufe'ulungaki and Benson (2002) have argued against non-Pacific educational ideas for their espoused failure to deliver. While such explanations are valid, they do not lend themselves easily to a sincere debate. Often, proponents of opposing research orientations see such arguments as political and therefore respond to them politically as well, Too often, they resort to gate-keeping techniques and power-wielding strategies, thereby sidelining or silencing genuine explanations by Pacific researchers.

It is therefore of more use for indigenous Pacific research to be conceptualized philosophically, as discussed above. Viewed in this way, discussions and debates on indigenous Pacific research can be done without need for bullying. With a philosophical presentation, the debate is inclusive. Its purpose is to educate and instruct. It allows for Pacific and other researchers to remove themselves from 'mud-slinging' about whether a questionnaire or a one-on-one meeting is the more culturally appropriate strategy to use in a particular situation. A philosophical approach encourages a disciplined attitude and builds confidence and academic credibility for Pacific researchers. So, what is the future for the development of indigenous Pacific research?
Future debates?

The future of indigenous Pacific research lies in developing Pacific research within its philosophical orientation. There is a temptation to step outside that orientation and to argue on someone else's turf. There is an urge to rebut, thinking one needs to keep one's mana in a manly fashion. There is a temptation for indigenous Pacific research to enter into a discussion, using another's modus operandi. These are tempting challenges and succumbing to them is likely to be time wasting, energy sapping and unproductive. Participating in a fight may be excused but doing so in an untimely manner is suicidal. It would be like walking on a dead end road. Indigenous Pacific research need not go down that path. It must not.

Indigenous Pacific research needs to be more of itself, first. It needs to know more of what it really is and what it is not. Indigenous Pacific research must paint all its shades of brown, while remaining true to its philosophical roots. Whatever the level of debate, indigenous Pacific research must be consistent with its fundamental nature. Within this, the need is to mark out what are unique, distinctive or similar and then to explain these adequately and logically, using the logic of indigenous Pacific research.

Many activities can happen. The need is for different kinds and levels of studies to be undertaken, including studies of clans, socio-economic groups, country, across-country and multiple country ones. Further need is for attention to each of the different levels of the debate. While Pacific researchers have tended to raise the issue of epistemology, this should not be seen as the only arena for debate. All the other philosophical levels should be debated so that the development of indigenous Pacific research in these areas is not neglected.

Resources that really matter for indigenous Pacific research are abundant within Pacific communities but these have been long marginalized. It will be a challenge to marshal these resources towards developing indigenous Pacific research. The academic leadership for indigenous Pacific research, however, is weak. This leadership base must be strengthened. As well, a deliberate developmental agenda should be created wherein emerging Pacific researchers are trained and mentored. The need is for a pioneering spirit - one that is able to leave behind a trail of firm foundations for future Pacific researchers to build on in developing indigenous Pacific research. 


\section{References}

Bakalevi, S. 2001, Ways of mathematising in Fijian society, Institute of Education, Suva.

Burrell, G. \& Morgan, G. 1992, Sociological paradigms and organizational analysis, Asgate, Hants.

Furivai, P. 2003, 'Rotuman educational ideas', in Educational Ideas from Oceania, ed. Thaman, pp. 104-105.

Gegeo, D. 1998, 'Indigenous knowledge and epistemology: Rural development examined from within', in The Contemporary Pacific, vol. 10 , no. 2, pp. 289-315.

Hereniko, V. 1995, 'Indigenous knowledge and academic imperialism', paper presented at the Contest Ground Conference, University of Hawaii, $6^{\text {th }}-9^{\text {th }}$ December, Honolulu.

Huffer, E. \& Qalo, R, 2004, 'Have we been thinking upside-down? The contemporary emergence of Pacific theoretical thought', in The Contemporary Pacific, vol. 16, no. 1, pp. 87-116.

Manu'atu, L. 2000, Tuli Ke Ma'u Hono Ngaahi Malie: Pedagogical possibilities for Tongan siudents in New Zealand secondary schooling, Unpublished PhD Thesis, University of Auckland.

Mel, M. 2003, 'Shifting cultures: Mbu - a proposal for a pluri-cultural perspective to culture in education in Papua New Guinea', in Educational ldeas from Oceania, ed. Thaman, pp. 36-45.

Nabobo, U. 2003, 'Indigenous Fijian educational ideas', in Educational Ideas from Oceania, ed. Thaman, pp. 85-93.

Nabobo, U. 1994, 'Exploring Yalomatua: Fijian education and the missing link', in Directions Journal of Educational Studies, vol. 16, no. 1 , pp. 41-54.

Pasikale, A. \& Tupuola, A. 1999, Creating successful students, Skill New Zealand, Wellington.

Pene, F., Taufe'ulungaki, A. \& Benson, C. 2002, Tree of Opportumity: Rethinking Pacific Education, Institute of Education, Suva.

Penetito, W. \& Sanga, K. 2002, 'A conversation on the philosophy and practice of teaching research in Maori and Pacific education', in New Zealand Annual Review of Education, Issue 12, pp. 21-38.

Sanga, K. \& Niroa, J. 2004, 'First steps and small beginnings in Vanuatu education research', in Rethinking Vanuatu Education Together; eds Sanga, Niroa, Institute of Pacific Studies, Matai \& Crowl, Suva.

Sanga, K. \& Pasikale, A. 2002, Research for Pacific empowerment: Guidelines for researching with Pacific commumities, EDRG, Auckland.
Taufe'ulungaki, A. 1994, 'Language community attitudes and their implications for he maintenance and promotion of the Tongan language', Directions Joumal of Educational Studies, vol. 16, no. 1, pp. 84-108.

Teaero, T. 2003, 'Indigenous education in Kiribati', in Educational Ideas from Oceania ed. Thaman, pp. 106-115.

Thaman, K. 2003, 'A conceptual framework for analyzing Pacific educational ideas: the case of Tonga', in Educational Ideas from Oceania, ed Thaman, pp. 73-78.

Thaman, K. 1988, Ako and faiako: cultural values, educational ideas and teachers' role perceptions in Tonga, Unpublished $\mathrm{PhD}$ Thesis, The University of the South Pacific.

Tupuola, A. 2000, Making sense of human development: Beyond western concepts and tmiversal assumptions, Institute of Education, Suva. 
Researching Pacific and Indigenous

Peoples: Issues and Perspectives

\section{Victoria \\ UNIVERSITY OF WELLINGTON \\ Te Whare Wânanga \\ atclípoko o fe Ikn a Máui

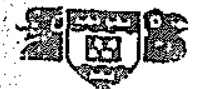 \\ LIBRARY}

Edited by

Tupeni L Baba

'Okusitino Mähina

Nuhisifa Williams

Unaisi Nabobo-Baba

Centre for Pacific Studies The University of Auckland 
CCentre for Pacific Studies, The University of Auckland, 2004

This book is copyright. Apart from those uses which may be permitted under the Copyright Act 1968 as amended, no part may be reproduced by any process without written permission from the publisher.

ISBN 0-908959-07-9

ISBN Agency

National Library of New Zealand

PO Box 1467

Wellington

\section{Dedication}

In memory of the late Dr Rusiate R. Nayacakalou, the first Pacific scholar to have attained a $\mathrm{PhD}$ degree, setting the intellectual height for us all through his great academic pursuit.

Cover Design \& Artwork: Kolokesa Mähina \& Noelle Brown, in memory of Malakai Māhina.

Pagesetting: Julie Sophai Solomua Maru Talagi

Printer: Astra Printer

VIGTORIA UNIVERSTTV OF WELLLINGTON 


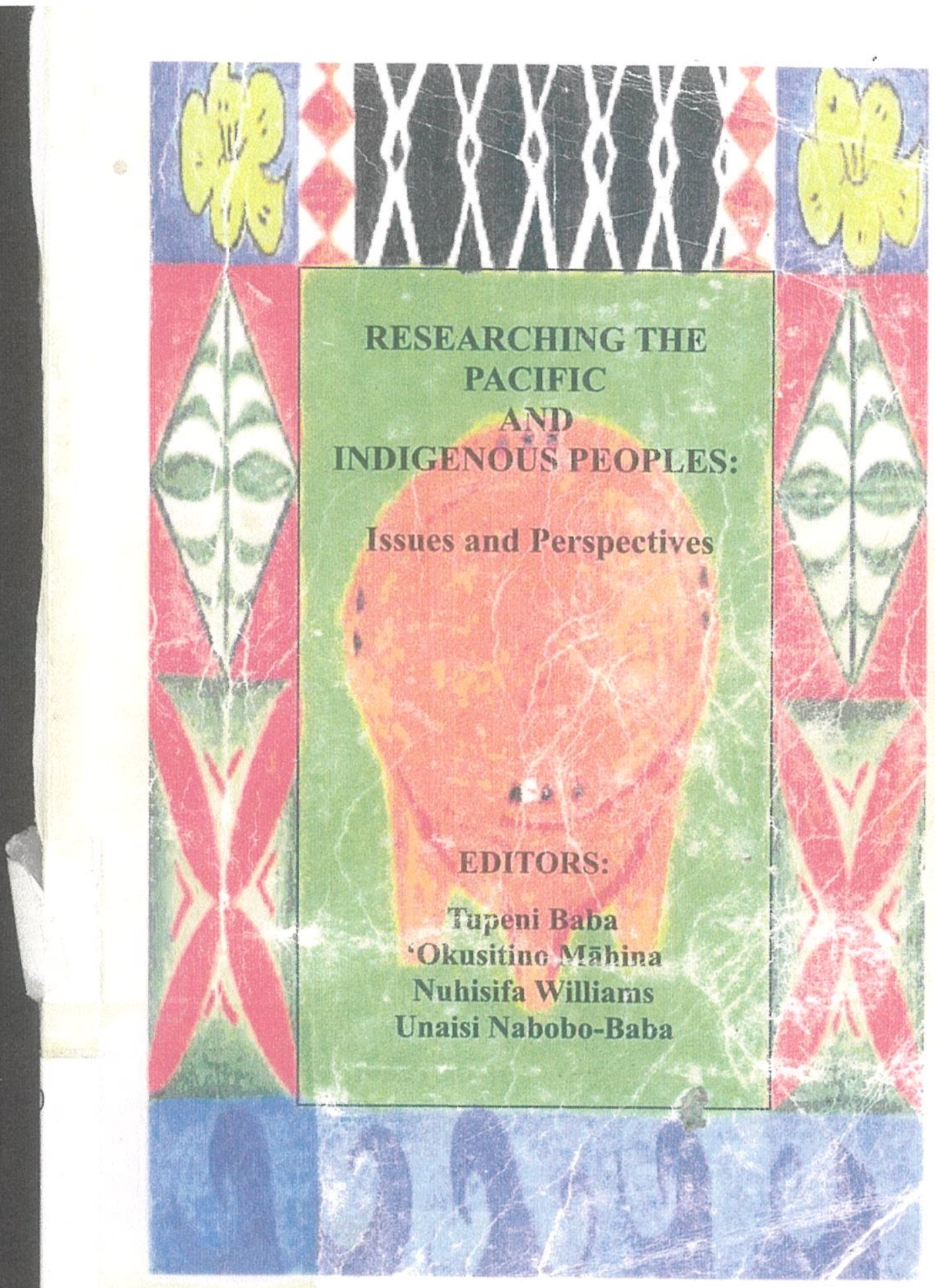

